\title{
HEMIPARETIC CEREBRAL PALSY: CLINICAL DATA COMPARED WITH NEUROIMAGING
}

\author{
Turolla de Souza RC ${ }^{1}$, Ciasca SM ${ }^{2}$, Moura-Ribeiro MVL ${ }^{2}$, Zanardi VA ${ }^{2}$ \\ ${ }^{1}$ Serviço de Fisioterapia e Terapia Ocupacional, Hospital das Clínicas, Universidade Estadual de Campinas - Unicamp, \\ Campinas, SP \\ ${ }^{2}$ Faculdade de Ciências Médicas, Unicamp, Campinas, SP \\ Correspondence to: Regina Célia Turolla de Souza, Serviço de Fisioterapia e Terapia Ocupacional, Hospital das \\ Clínicas, Universidade Estadual de Campinas, $2^{\circ}$ andar, CEP 13083-970, Campinas, SP \\ e-mail: reginaturolla@yahoo.com.br
}

Received: 07/10/2004 - Accepted: 21/02/2006

\begin{abstract}
Objective: The present study correlated fine motor function (FMF) and sensory function (SF) performance with magnetic resonance imaging classification, in cases of hemiparetic cerebral palsy. Method: Specific protocols were used to evaluate FMF, SF and brain lesion extent and location in the hemisphere. Forty-six patients were assessed: 23 with hemiparetic cerebral palsy (group 1) and 23 normal individuals (group 2). Their ages ranged from 7 to 16 years, with a mean of 12 years and 8 months. Results: FMF and SF performance in group 1 was significantly worse than in group 2. Hemiparetic cerebral palsy cases with lesions in only one brain structure presented better results than those with two or more damaged structures larger than $10 \mathrm{~mm}$. Patients with unilateral or bilateral cortical and subcortical impairment presented worse performance than those with subcortical lesions. Conclusion: Motor and sensory dysfunctions need to be identified and understood in order to provide routine training and special care for such children.
\end{abstract}

Key words:cerebral palsy, neuroimaging, fine motor function, sensory function.

\section{RESUMO}

\section{Paralisia Cerebral Hemiparética: Dados Clínicos Comparados à Neuroimagem}

Objetivo: Este estudo correlacionou o desempenho da função motora fina (FMF) e Sensorial (FS) na paralisia cerebral hemiparética (PC-H) à classificação da ressonância magnética (RM). Método: Utilizaram-se os protocolos específicos para avaliar FMF, FS e lesões encefálicas quanto à sua extensão e localização no hemisfério. Foram avaliados 46 sujeitos sendo 23 com PC$\mathrm{H}$, grupo 1, e 23 crianças normais, grupo 2. A idade variou entre 07 a 16 anos, idade média de 12 anos e 8 meses. Resultados: $\mathrm{O}$ desempenho das FMF e FS demonstrou ser significantemente pior no grupo 1 quando comparado ao grupo controle. PC-H que apresentavam lesões atingindo uma única estrutura encefálica demonstraram melhores resultados que aqueles com comprometimento atingindo duas estruturas maiores que $10 \mathrm{~mm}$. O desempenho dos sujeitos com comprometimento cortical e subcortical, uni ou bilateral, foi inferior quando comparados aos com lesões subcorticais. Conclusão: As disfunções motoras e sensoriais necessitam ser identificadas e compreendidas para prover melhor treinamento de rotina e cuidados especiais a essas crianças.

Palavras-chave: paralisia cerebral, neuroimagem, teste de movimentos finos e de sensibilidade. 


\section{INTRODUCTION}

Cerebral palsy is a disorder caused by brain damage before or during birth, or during the early years of life, that results in loss of voluntary muscular control and coordination. Although its exact cause is unknown, the apparent predisposing factors include disease, very low infant birth weight, and injury or physical abuse. Maternal smoking, alcohol consumption and ingestion of certain drugs can also contribute. Many cases are thought to be due to oxygen deficiency during the birth process. The severity of the affliction is dependent on the extent of the brain damage. Those with mild cases may have only a few affected muscles, while severe cases can result in total loss of coordination or paralysis ${ }^{1,2,3,4}$.

A child affected by cerebral palsy usually presents some decrease in muscle strength, sensitivity and coordination in the upper limbs ${ }^{5}$. It is the upper limbs that support fine motor capabilities, while they also have an important role in gross motor capabilities ${ }^{6}$. These capabilities may be changed by many factors, such as muscle tone ${ }^{7}$ and the way in which sensory information is processed to maintain movements ${ }^{6}$. Hemiparetic cerebral palsy, i.e. paralysis of one complete side of the body including the arm, trunk and leg, is one of the most common types of cerebral palsy referred to in the literature and is classified as a subdivision of spastic cerebral palsy ${ }^{8}$.

The development of neurological imaging techniques like magnetic resonance (MRI) has allowed the consequences of brain injury to be studied. Such studies are important because they enable correlation between the exact location of the lesion and clinical findings $9,10,11$.

Gaining an understanding of exactly what causes neuromotor disturbances is a complex process, because such patients' disabilities involve several neurological deficits. Studies on children with cerebral palsy have shown that different lesions give rise to a variety of specific and generalized disorders.

\section{SUBJECTS AND METHOD}

This study included twenty-three children aged between 7 years 10 months and 16 years 6 months (mean age of 12 years 8 months), with a diagnosis of hemiparetic cerebral palsy of prenatal or perinatal etiology. These children were selected following MRI assessment, from the data bank of the cerebral palsy outpatient treatment facility of the Pediatric Neurology Center of the School of Medical Sciences, University of Campinas (UNICAMP). Two groups were constituted: Group 1 (G1), comprised of children with hemiparetic cerebral palsy, and Group 2 (G 2) with normal children matched for age and sex with the G1 children.

The exclusion criteria included: central nervous system (CNS) impairment, postnatal etiology, genetic syndromes, level of cognitive understanding that could impair the assessment, and musculoskeletal impairment. (Table 1).

The protocol proposed by Beckung ${ }^{13}$ was partially used for evaluating fine motor function (FMF) and sensory function (SF). The results were graded according to the following schema: "0" non-functioning, "1" poor, "2" good, and "3" normal. The abilities used for evaluating FMF were: pincer grasp (using finger tips to grasp a pencil, to grasp a cylinder, to grasp with the palm, and to hold a key); to insert a coin in a slot; to pin thumbtacks (drawing pins) on a picture; to pour water from one glass to another; to fasten a nut and bolt; to put beads on a string; to oppose thumb and finger; and hand strength (with trial grip) (Figures 1 and 2).

To assess sensory functions the following features were used: sense of balance, sensing of vibration, touch, pain, temperature, distinguishing sharp objects, stereognosis, graphesthesia, distinguishing between two points; extinction (Figure 3).

The magnetic resonance images were assessed in accordance with the criteria proposed by Okumura ${ }^{14,15}$, as modified by Piovesana ${ }^{16}$ according lesion extent and location in the brain hemisphere.

\section{Lesion extent:}

1- Only one brain structure smaller than $10 \mathrm{~mm}$ affected;

2- Only one brain structure larger than $10 \mathrm{~mm}$ affected;

3- Two brain structures larger than $10 \mathrm{~mm}$ affected;

4- Bilateral involvement.

\section{Lesion location in the hemisphere:}

1- Subcortical area;

2- One restricted brain lobe-cortical area; cortical and subcortical areas;

3- Subcortical and/or cortical lesions involving both hemispheres.

The Wilcoxon test was used to evaluate related samples, and also Spearman's linear correlation and the Mann-Whitney and Kruskal-Wallis tests. The statistical significance level adopted was $5 \%(\mathrm{p}<0.05)$. Simple percentages were calculated and descriptive tables were produced.

The Research Ethics Committee of the School of Medical Sciences, UNICAMP, gave its approval for this study. The adults responsible for these children signed a statement granting their free and informed consent.

\section{RESULTS}

Fifteen patients $(65 \%)$ presented hemiparetic cerebral palsy on the right side and eight (35\%) on the left side; fourteen $(61 \%)$ were females and nine (39\%) were males. Prenatal and perinatal etiology was observed in eleven patient (48\%), perinatal alone in seven $(30 \%)$ and prenatal alone in two $(9 \%)$, while the etiology was undetermined in three cases (13\%). Thirteen patients $(56 \%)$ were born at full term (37 weeks 
Table 1. Clinical Data, hemiparetic cerebral palsy patients.

\begin{tabular}{|c|c|c|c|c|c|c|}
\hline Subject & Hemiparesis & Etiology & $\begin{array}{l}\text { Length of } \\
\text { Gestation }\end{array}$ & Lesion extent & Location & $\begin{array}{l}\text { Diagnostic } \\
\text { hypothesis }\end{array}$ \\
\hline 1 & $\mathrm{~L}$ & Pre + Peri & $<34$ weeks & NL & NL & NL \\
\hline 2 & $\mathrm{R}$ & Undet & Full term & 1 structure $>10 \mathrm{~mm}$ & $\mathrm{SC}$ & Neuroplastic lesion \\
\hline 3 & $\mathrm{R}$ & Peri & Full term & 2 structures $>10 \mathrm{~mm}$ & $\mathrm{C}+\mathrm{SC}$ & Encephalomalacia \\
\hline 4 & $\mathrm{~L}$ & Pre + Peri & Full term & 1 structure $\leq 10 \mathrm{~mm}$ & $\mathrm{C}+\mathrm{SC}$ & CVA \\
\hline 5 & $\mathrm{R}$ & Undet & Full term & 2 structures $>10 \mathrm{~mm}$ & $\mathrm{C}+\mathrm{SC}$ & CVA \\
\hline 6 & $\mathrm{~L}$ & Pre + Peri & $\geq 34$ weeks & Bil disorder & $\mathrm{SC}$ & PVL \\
\hline 7 & $\mathrm{R}$ & Pre + Peri & Full term & 1 structure $>10 \mathrm{~mm}$ & $\mathrm{SC}$ & PVL \\
\hline 8 & $\mathrm{~L}$ & Pre + Peri & $\geq 34$ weeks & 2 structures $>10 \mathrm{~mm}$ & $\mathrm{C}+\mathrm{SC}$ & CVA \\
\hline 9 & $\mathrm{R}$ & Pre + Peri & $<34$ weeks & 1 structure $>10 \mathrm{~mm}$ & $\mathrm{SC}$ & PVL \\
\hline 10 & $\mathrm{R}$ & Pre + Peri & $\geq 34$ weeks & 2 structures $>10 \mathrm{~mm}$ & $\mathrm{C}+\mathrm{SC}$ & Undet \\
\hline 11 & $\mathrm{R}$ & Peri & $\geq 34$ weeks & Bil disorder & Bil C and/or SC & Lacunar lesion \\
\hline 12 & $\mathrm{R}$ & Peri & $<34$ weeks & 1 structure $>10 \mathrm{~mm}$ & $\mathrm{C}+\mathrm{SC}$ & PVL \\
\hline 13 & $\mathrm{R}$ & Pre + Peri & Full term & 2 structures $>10 \mathrm{~mm}$ & $\mathrm{C}+\mathrm{SC}$ & Lacunar lesion \\
\hline 14 & $\mathrm{R}$ & Pre & Full term & 1 structure $\leq 10 \mathrm{~mm}$ & S C & CVA \\
\hline 15 & $\mathrm{~L}$ & Peri & $<34$ weeks & 1 structure $\leq 10 \mathrm{~mm}$ & $\mathrm{SC}$ & PVL \\
\hline 16 & $\mathrm{~L}$ & Pre + Peri & Full term & 2 structures $>10 \mathrm{~mm}$ & $\mathrm{C}+\mathrm{SC}$ & CVA \\
\hline 17 & $\mathrm{R}$ & Peri & Full term & 2 structures $>10 \mathrm{~mm}$ & $\mathrm{C}+\mathrm{SC}$ & Porencephaly \\
\hline 18 & $\mathrm{~L}$ & Peri & Full term & 1 structure $\leq 10 \mathrm{~mm}$ & $\mathrm{SC}$ & CVA \\
\hline 19 & $\mathrm{R}$ & Pre + Peri & Full term & Bil disorder & Bil C and/or SC & PVL \\
\hline 20 & $\mathrm{~L}$ & Pre & Full term & 1 structure $>10 \mathrm{~mm}$ & Bil C and/or SC & PVL \\
\hline 21 & $\mathrm{R}$ & Peri & $<34$ weeks & 2 structures $>10 \mathrm{~mm}$ & $\mathrm{SC}$ & PVL \\
\hline 22 & $\mathrm{R}$ & Undet & Full term & 1 structure $>10 \mathrm{~mm}$ & $\mathrm{SC}$ & PVL \\
\hline 23 & $\mathrm{R}$ & Peri & $<34$ weeks & Bil disorder & $\mathrm{S} \mathrm{C}$ & Bilateral PVL \\
\hline
\end{tabular}

The instruments used for evaluating fine motor function and sensory function are presented in Figures 1, 2 and 3.

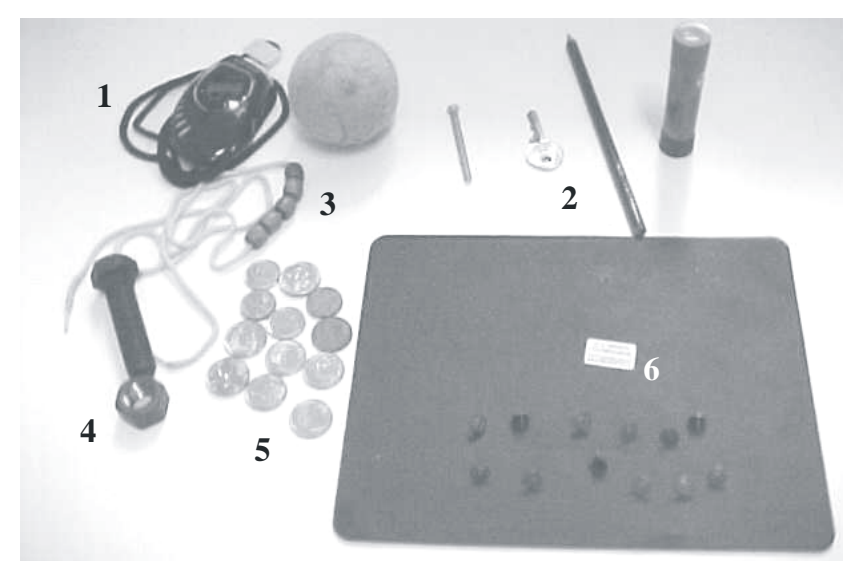

Figure 1. Evaluation kit for fine motor function: 1- digital chronometer; 2- material for evaluation of holding and grasping: ball, screw, key, pencil and cylinder; 3- counting beads; 4- nut and bolt; 5- coins for inserting in slot; 6- thumbtacks (drawing pins) on picture.

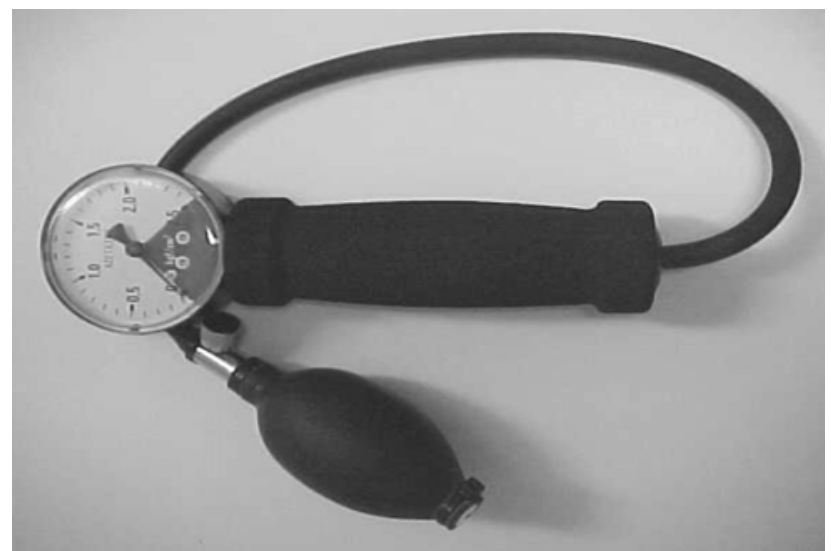

Figure 2. Grip test 


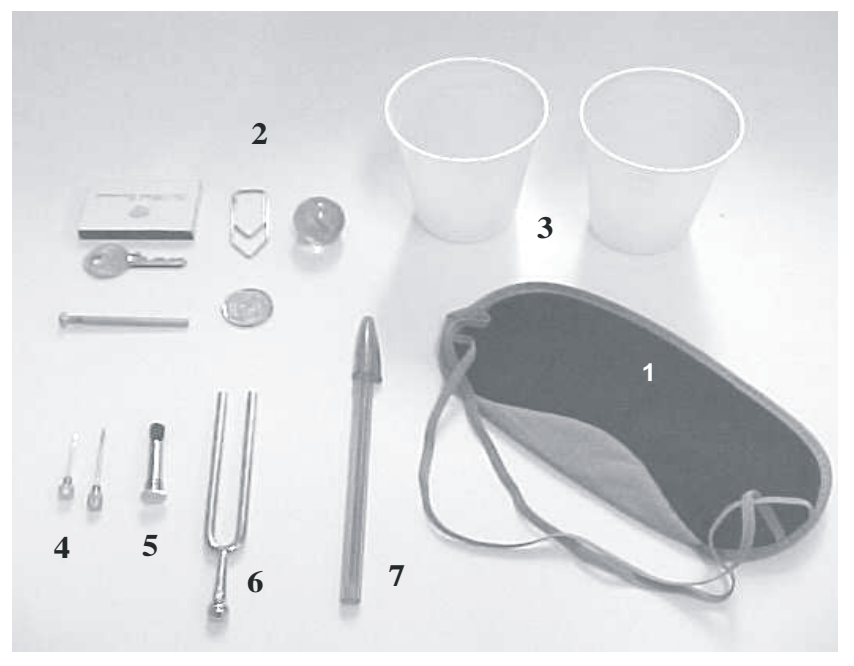

Figure 3. Sensitivity evaluation kit: 1- blindfold; 2- material for evaluating stereognosis: matchbox, key, screw, paper clips, coin and small ball; 3- different cups for temperature test; 4- sharp-pointed object; 5- brush; 6- pins; 7-gapped object (prongs).

6 days to 42 weeks), while four (18\%) were premature with gestation of more than 34 weeks and six $(26 \%)$ were premature with gestation of less than 34 weeks. The hemiparetic cerebral palsy patients with gestation less than 34 weeks presented the best performance for fine motor function, which was significantly different from the others ( $\mathrm{p}=0.0014$; Kruskal-Wallis test).

With regard to the extent of the lesion, eight patients (35\%) presented lesions larger than $10 \mathrm{~mm}$, six (26\%) presented two encephalic structures greater than $10 \mathrm{~mm}$, four $(17.5 \%)$ presented bilateral injury, four $(17.5 \%)$ presented a structure of less than $10 \mathrm{~mm}$, and one was normal (4\%). The hemispheric location involved the subcortical area in ten patients (43.5\%), the cortical and subcortical areas in nine (39\%), and the cortical and/or subcortical areas on both hemispheres in three (13.5\%), while one case was normal (4\%). Lesions in only one lobe were not observed. Significant abnormalities were found on neurological imaging of 22 hemiparetic cerebral palsy patients. One of these patients showed a normal computed tomography scan (CT) and MRI, while presenting a clinical pattern of slight spastic hemiparesis. The diagnosis revealed periventricular leukomalacia (PVL) in nine children (39\%), cerebrovascular accident (CVA) in six children $(26 \%)$ and other categories of hemiparesis in seven children $(31 \%)$, while there was one normal case $(4 \%)$.

FMF analysis for the two groups gave a mean of 2.02 for G1 and 2.72 for G2. The statistical difference in performance between $\mathrm{G} 1$ and $\mathrm{G} 2$ was significant $(\mathrm{p}<0.0001$ ) and showed that the hemiparetic cerebral palsy patients had worse performance. Sensory function in G1 presented a mean of 2.81 and $\mathrm{G} 2$ presented 3.00. Comparing the performance of the two groups, the hemiparetic cerebral palsy patients presented worse results $(\mathrm{p}<0.0001)$ (Table 2).
Table 2. Fine motor function and sensory function in Groups 1 and 2 .

\begin{tabular}{cccccc}
\hline Group & Variable & $\mathrm{N}$ & Mean & SD & p-value* \\
\hline G1 & FMF & 23 & 2.02 & 0.41 & $<0.0001$ \\
G2 & FMF & 23 & 2.72 & 0.10 & \\
G1 & SF & 23 & 2.81 & 0.21 & $<0.0001$ \\
G2 & SF & 23 & 3.00 & 0.00 & \\
\hline
\end{tabular}

*Wilcoxon test for related samples; SD: standard deviation.

\section{Correlation between fine motor function and sensory function}

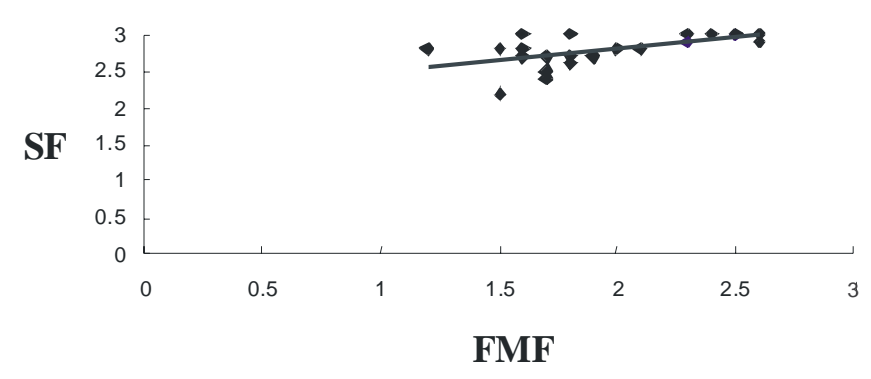

Correlation between FMF and SF $(r=0.57382 ; \mathrm{p}=0.0042)$.

Figure 4. shows that there was a statistically significant correlation between fine motor function and sensory function $(r=0.57382)$, using Spearman's linear correlation.

The fine motor function performance among hemiparetic cerebral palsy patients with a lesion in only one brain structure was better than among those with lesions in two structures larger than $10 \mathrm{~mm}(\mathrm{p}=0.0275$; Kruskal-Wallis test $)$.

In correlating the fine motor function and sensory function results with lesion location in the hemisphere, the patients with lesion in the cortical and subcortical areas on one side or both sides presented worse results than those with lesions only in subcortical areas, for both functions (respectively, $\mathrm{p}=0.0200$ and $\mathrm{p}=0.0141$; Mann-Whitney test) (Figure 4).

\section{DISCUSSION}

In this study, the right side was affected in $64 \%$ of the patients. Right-side hemiparesis is often found, according to the literature. Several studies have shown that males are more affected but, contrary to the prevailing data in the literature ${ }^{16,17}$, the present study showed that females were more affected. Prenatal and perinatal etiology was found in $45 \%$ of the patients, while the etiology was perinatal in $32 \%$, 
prenatal in 9\% and undetermined in $14 \%$. Piovesana et al. ${ }^{9}$ evaluated 175 children and found prenatal etiology in $23 \%$, perinatal in $18 \%$ and undetermined in $5 \%$.

Two common findings in this study were PVL (45\%) and CVA (27\%). The brain pathology types and their relative frequencies were similar to those found in other hemiparetic cerebral palsy studies ${ }^{19,18,16,12}$. In addition, bilateral lesion was found in three out of the 23 patients. This was also reported by Steinlen et al. ${ }^{9}$ (8/33 patients) and Niemann et al. ${ }^{10}(8 / 41$ patients).

PVL consists of necrosis of the white matter. It has characteristic distribution: the dorsal and lateral white matter surrounds the semi-oval centers of the optic and acoustic radiating centers, toward the external angle of the lateral ventricle. PVL presents different pathological factors, but these consist mainly of periventricular focal necrosis and diffuse lesions in the white matter. Focal necrosis occurs mainly in the distribution zone where arteries penetrate. The fibers of the cortical spinal tract that descend to the lower limbs are affected more than the fibers that go to the upper limbs and face ${ }^{19}$. This may explain why the best FMF performance was obtained from patients with subcortical injuries.

A correlation between FMF and SF performance was found. This finding concords with those from the studies by Uvebrant ${ }^{17}$ and Piovesana ${ }^{15}$. These authors mentioned that hemiparetic cerebral palsy cases frequently present disturbances in stereognosis sensitivity that impairs motor function. They also reported that children with congenital hemiplegia born at full term are more acutely affected than those born prematurely.

Boyce et al. ${ }^{20}$ reviewed the figures and features of tools for movement evaluation in cerebral palsy cases. In fact, no tool is sensitive enough for measuring the performance of such children. Nevertheless, the present case series could establish a pattern for FMF deficits presented by hemiparetic cerebral palsy, through using such tools.

The present study gives valuable information on correlations between FMF, SF and neurological imaging, for hemiparetic cerebral palsy cases. The tests applied showed correlations between neurological integrity and the types of neurological lesions. Such correlations are important for obtaining more accurate prognoses. It is essential to provide neurological training for professionals involved in caring for such cases, with regard to the relationship between brain lesions and functional losses. Only in this way will it be possible to establish programs for assisting such patients.

\section{CONCLUSION}

The results from this study suggest that there is a close relationship between impaired fine motor function and cortical lesions. Neurological imaging was essential for establishing correlations between lesion extent and fine motor function.
Overall, this study achieved its aim of correlating brain lesions with neurological motor dysfunctions. The knowledge that specific brain lesions correlate with specific functions in hemiparetic cerebral palsy cases is significant, since sensory malfunction needs to be identified and understood in order to provide better routine training and special care for such children.

Acknowledgments: We wish to acknowledge the assistance provided by staff within the Children and Adolescent Integration and Development Program of UNICAMP; the Research and Statistics Committee of the School of Medical Sciences, UNICAMP; the parents and children who took part in these evaluations and enabled the development of this study; and especially Professor Dr. Ana Maria Sedrez Gonzaga Piovesana (in memoriam), who stimulated us to do this work.

\section{REFERENCES}

1. Kuban KCK, Leviton A. Cerebral palsy. N Engl J Med. 1994 Jan 20; 330(3): 188-95

2. Hagberg B, Hagberg G, Olow I, Von Wendt L. The changing panorama of cerebral palsy in Sweden. VII. Prevalence and origin in the birth year period 1987-90. Acta Paediatr Scand 1996 August 85(8): 954-60.

3. Thickroom GW, Byrnes ML, Archer SA, Nagarajan L, Mastaglia FL. Differences in sensory and motor cortical organization following brain injury early in life. Ann Neurol 2001 Mar; 49(3): 320-7.

4. Rotta NT. Paralisia cerebral, novas perspectivas terapêuticas. J Pediatr 2002 Jul; 78 (1): 548-54.

5. Pierce SR, Daly K, Gallagher KG, Gershkoff AM, Schaumburg SW. Constraint-induced therapy for a child with hemiplegic cerebral palsy: a case report. Arch Phys Med Rehabil 2002 Oct; 83(10): 1462-3.

6. Shumway-Cook A, Woollacott MH. 2001. Motor Control (section 1). Lippincott Williams \& Wilkins, $2^{\text {nd }}$ ed, Philadelphia, USA.

7. Iwabe C, Piovesana AMSG. Estudo comparativo do tono muscular na paralisia cerebral tetraparética em crianças com lesões predominantemente corticais ou subcorticais na tomografia computadorizada de crânio. Arq Neuropsiquiatr 2003 Sep; 61(3A): 617-20.

8. Piovesana AMSG, Moura-Ribeiro MVL, Zanardi. VA, Gonçalves, VMG. Hemiparetic cerebral palsy: etiological risk factors and neuroimaging. Arq Neuropsiquiatr 2001 Mar; 59(1): 29-34.

9. Steinlin M, Good M, Martain E, Bnziger O, Largo RH, Boltshauser E. Congenital hemiplegia: morphology of cerebral lesions and pathogenetic aspects from MRI. Neuropediatrics. 1993 Aug; 24(4): 224-9.

10. Niemann G, Krageloh-Mann I, Grodd W, Michaelis R. Congenital hemiparesis and periventricular leukomalacia: pathogenic aspects on magnetic resonance imaging. Dev Med Child Neurol 1994 Nov; 36(11): 943-50. 
11. Humphreys P, Whiting S, Pham B. Hemiparetic cerebral palsy: clinical pattern and imaging in prediction of outcome. Can J Neurol Sci. 2000 Aug; 27(3): 210-9.

12. Beckung E. Development and validation of a measure of motor and sensory function in children with epilepsy. Pediatric Therapy 2000 Aug;(2): 2435.

13. Okumura A, Hayakawa F, Katu T, Kuno K, Watanabe K. MRI findings in patients with spastic cerebral palsy. I: correlation with gestational age at birth. Dev Med Child Neurol 1997a Jun; 39(6): 363-8.

14. Okumura A, Hayakawa F, Katu T, Kuno K, Watanabe K. MRI findings in patients with spastic cerebral palsy. II: correlation with type of cerebral palsy. Dev Med Child Neurol 1997b Jun; 39(6): 369-72.

15. Piovesana AMSG. Paralisia Cerebral Hemiparética: Aspectos Evolutivos, plasticidade Cerebral e Especialização Hemisférica [Doctoral Thesis, UNICAMP] 1999.
16. Goutiéres F, Challamel MJ, Aicardi JE, Gilly R. Congenital hemiplegia: semiology, etiology and prognosis. Arch Fr Pediatr 1972 Oct; 29(8): 839-51.

17. Uvebrant P. Hemiplegic cerebral palsy. Aetiology and outcome. Acta Paediatr Scand Suppl 1988; 345: 1-100.

18. Kotlarek F, Rodewig R, Brull D. Computed tomographic findings in congenital hemiparesis in childhood and their relation to etiology and prognosis. Neuropediatrics 1981 May; 12(2): 1019.

19. Volpe JJ. Brain injury in the premature infant - from pathogenesis to prevention. Brain Dev 1997 Dec; 19(8): 519-34.

20. Boyce WF. Measuring quality of movement in cerebral palsy: a review of instruments. Phys Ther 1991 Nov; 71(11): 813-9. 